\title{
Analysis of ocular injury 1-year outcome in survivors of Beirut Port ammonium nitrate blast
}

\author{
Ahmad M. Mansour ${ }^{1}$ (D) Daniel G. Cherfan ${ }^{2} \cdot$ Alex Jalkh $^{3} \cdot$ Ferenc Kuhn $^{4,5,6}$ \\ Received: 13 December 2021 / Revised: 21 January 2022 / Accepted: 23 January 2022 / Published online: 31 January 2022 \\ (c) The Author(s), under exclusive licence to Springer-Verlag GmbH Germany, part of Springer Nature 2022
}

\begin{abstract}
Purpose Ascertain the 1-year outcome of patients who sustained open eye injuries from the Beirut Port ammonium nitrate (AN) explosion, one of the most powerful non-nuclear explosions in history.

Methods Retrospective chart review of the operated eyes in 2 major eye hospitals.

Results Out of 42 patients with open globe injury that was originally sutured, 29 patients ( 34 eyes) were followed at the 1 -year mark. The initial vision in $\log \mathrm{MAR}($ mean $\pm \mathrm{SD}$ ) was $2.93 \pm 0.87$ (hand motion equivalent) and the final vision was $1.80 \pm 1.47$ (counting finger $2 \mathrm{~m}$ equivalent). No light perception (NLP) vision was noted in 12 eyes on presentation and 10 eyes remained so, while 2 eyes reached light perception (LP) vision. Eight eyes had an intraoperative expulsive choroidal hemorrhage (7 NLP and 1 LP both pre- and postoperatively), and 6 of the 8 developed phthisis. All eyes that developed phthisis had NLP preoperatively and postoperatively. Ocular Trauma Score (OTS) correlated inversely with both initial and final vision $(p<0.001)$. Zone of injury inversely correlated with initial vision $(p=0.02)$ and positively with final vision $(p<0.001)$. Final vision was significantly worse in zone 3 vs. zones 1 and $2(3.2 \pm 0.5)$ vs. $0.9 \pm 1.1)(p<0.001)$ injuries, as was the initial vision $(3.3 \pm 0.5$ vs. $2.7 \pm 0.8 ; p=0.002)$.

Conclusion The OTS, which provides prognostic information for serious ocular trauma, also yields valuable prognostic information for AN-associated ocular injuries. Expulsive choroidal hemorrhage and NLP vision at presentation remain very poor prognostic signs.
\end{abstract}

\section{Key messages}

- Ocular Trauma Score offers a good prognostic model in ocular trauma in general.

- In one of the biggest non-nuclear ammonium nitrate blast in Beirut Port, NLP initial vision and intraoperative expulsive choroidal hemorrhage were the most ominous prognostic variables

- Ocular Trauma Score correlated inversely with initial and final vision in Beirut Port blast

- Ocular trauma score yielded valuable prognostic information for ammonium nitrate-associated ocular injuries.

Keywords Ammonium nitrate explosion - Beirut port explosion · Pars plana vitrectomy · Trauma $\cdot$ Retinal detachment . Expulsive choroidal hemorrhage · Ocular Trauma Score · Zone of injury · Intraocular foreign body · Ocular laceration · Ocular rupture

Ahmad M. Mansour

ammansourmd@gmail.com

Ferenc Kuhn

fkuhn@mindspring.com

Extended author information available on the last page of the article

\section{Introduction}

A consignment of an estimated 2750 tons of discretely and unsafely stored ammonium nitrate (AN) $\left(\mathrm{NH}_{4} \mathrm{NO}_{3}\right)$ in the warehouse facility of the port of Beirut exploded at 6:05 pm 
on August 4, 2020, destroying a large part of the capital of Lebanon, killing 218, wounding some 14,000 people [1], and leaving around 300,000 residents homeless [2,3]. Wounded individuals were rushed to still-functional hospitals (those that did not sustain major structural damage), which in turn became severely overcrowded in $2 \mathrm{~h}$. The blast lofted a white mushroom cloud over the Lebanese capital with two million inhabitants and is considered the most severe anthropological disaster of the decade with a consequent direct and indirect financial and economic loss edging 10 billion US dollars [1-3]. The Beirut Port explosion traumatized the living population after a series of political unrest, COVID-19 outbreak, security challenges, and unprecedented economic collapse, transforming Lebanon from a functioning nation to a failing one. Hunger, poverty, lack of medications, fuel shortage, and continuous electricity outage were accompanied by a vast emigration of medical personnel.

Most of the literature have dealt with the immediate human bodily injuries and economic aftermath of collapsed historic buildings [1-3]. Except for a few reports [4-10], publications on major nuclear or major non-nuclear disasters did not focus on ocular injuries, and those that did tackled only the acute phase. Our aim is to analyze the long-term visual sequelae of the Beirut blast in the two largest eye hospitals, excluding eye-injury patients treated at general hospitals.

\section{Materials and methods}

This was a retrospective case review of patients who were treated for eye injuries within $54 \mathrm{~h}$ of the blast. Additionally, we included patients who had suturing of the ocular ruptures and lacerations on the day of the blast in a general hospital and were referred for further management within $54 \mathrm{~h}$ of the blast. Exclusion criteria included patients who failed their 1-year follow-up. For this purpose, the databases of the hospitals were searched for the operated-on patients with ocular blast injuries. All applicable institutional regulations concerning the accessing of medical notes for research purposes were observed by obtaining institutional review board (BESH N.4072021 and EEI N.8112020) approval. The study adhered to the Declaration of Helsinki.

Primary corneal and scleral full-thickness wounds were sutured by attending ophthalmologists. The situation did not allow detailed preoperative tests such as B-scan ultrasonography or any radiographic evaluation. Postoperative evaluation included slit-lamp bio-microscopy and indirect ophthalmoscopy in addition to B-mode ultrasonography and SD-OCT.

The recorded data included age, gender, laterality, initial visual acuity, and anterior and posterior segment examinations. The type of injury $[11,12]$ (rupture, penetration, intraocular foreign body [IOFB], perforation), and the zone of injury (ZOI) (zone 1 (wound limited to cornea), zone 2 (wound of sclera and no more posterior than $5 \mathrm{~mm}$ from the limbus), and zone 3 (wound posterior to anterior $5 \mathrm{~mm}$ of sclera)) were recorded. The Ocular Trauma Score $[11,12]$ (OTS) and the ZOI were determined retrospectively by 2 senior surgeons (AMM, AJ) based on the sketch of the injury on admission notes, operative findings, and follow-up notes.

All reports concerning major ammonium nitrate explosions from 1900 to the present were searched for ocular injuries using PubMed or Google Scholar databases using the search term "ammonium nitrate disaster" [13]. The records were screened for estimated weight of the ammonium nitrate, number of fatalities, number of wounded, and ocular injuries especially in regard for open globe trauma.

Statistical analyses were carried using the Mann-Whitney $U$ test for small numbers below 30 and the Pearson correlation coefficient. Statistical significance was set at $p<0.05$.

\section{Results}

The two eye hospitals near the blast were Beirut Eye Specialty Hospital (BESH) and Eye and Ear International (EEI). BESH is located $3.9 \mathrm{~km}$ (2 miles) from the blast site and had a total of 46 admissions to the emergency room with various ocular injuries; 11 patients with open eye injury were operated there with 10 returning for the 1-year follow-up. EEI is located $11 \mathrm{~km}$ (6 miles) from the Beirut Port; it had 31 admissions to the emergency room, all with open eye injury and all were operated on, with 19 patients available for the 1-year follow-up. In all, 29 out of 42 originally operated-on patients constituted the patient population for the current report. Twenty-four patients had unilateral and five had bilateral trauma (Table 1), making the number of eyes included in this study 34. All cases were operated within hours of admission to the emergency room. The surgeons kept operating until late on the night of the blast. Enucleation was not carried out on that night of the blast as all wounds were deemed amenable to suturing.

The mean age was $44.4 \pm 18.8$ years with a slight male preponderance (17 men and 12 women). The mean initial vision in $\log$ MAR (mean $\pm \mathrm{SD}$ ) was $2.93 \pm 0.87$ (hand motion [HM] equivalent) and the final vision was $1.80 \pm 1.47$ (counting finger $[\mathrm{CF}] 2 \mathrm{~m}$ equivalent) (Table 2). No light perception vision (NLP) was noted in 12 eyes on presentation and 10 eyes maintained so while 2 eyes reached light perception (LP) vision. The visual acuity was unchanged in 11 eyes, improved in 22 (with a mean visual gain of 1.11 logMAR or 11 EDTRS lines), and worsened in 1 eye.

Eight eyes had an intraoperative expulsive choroidal hemorrhage (7 NLP and 1 LP both pre- and postoperatively), and 6 of the 8 developed phthisis (Table 3). Two eyes with 
Table 1 Clinical and ocular trauma characteristics of 29 patients with initial suturing of ocular lacerations and followed for 1 year after the Beirut Blast

\begin{tabular}{ll}
\hline Clinical variables & Mean (range) or number \\
\hline Age & $44.4(15-100)$ \\
Gender & 17 \\
Men & 12 \\
Women & \\
Laterality & 24 \\
Unilateral & 5 \\
Bilateral & \\
Injury type & 10 \\
Rupture & 13 \\
Penetrating & 11 \\
Perforating & \\
Location of laceration & 4 \\
Cornea & 20 \\
Corneosclera & 4 \\
Sclera & \\
ZOI & 8 \\
1 & 13 \\
2 & 13 \\
3 & $63.1(36-90)$ \\
OTS & 11 \\
Below 50 & 7 \\
$50-69$ & 16 \\
70 and above & \\
\hline
\end{tabular}

phthisis did not have recorded expulsive choroidal hemorrhage. All eyes that developed phthisis had NLP preoperatively and postoperatively. Glass injuries from balconies facing the Beirut Port represented most of the injuries: intraocular foreign bodies were removed in 6 cases and consisted of glass in 5 cases and metal in one case.

OTS (mean \pm SD 63.1 \pm 13.7 ) correlated inversely with both initial $(R=-0.82)$ and final vision $(R=-0.68)$

Table 2 Visual acuity at presentation and at the 1-year follow-up on 29 patients with sutured ocular lacerations following the Beirut Blast

\begin{tabular}{lll}
\hline Vision & Initial & 1-year \\
\hline NLP & 12 & 10 \\
LP & 7 & 2 \\
HM & 8 & 1 \\
$20 / 1600$ & 0 & 2 \\
$20 / 800$ & 3 & 2 \\
$20 / 400$ & 3 & 3 \\
$20 / 200$ & 1 & 1 \\
$20 / 100$ & 1 & 2 \\
$20 / 80$ & 0 & 1 \\
$20 / 50$ & 0 & 1 \\
$20 / 40$ & 0 & 2 \\
$20 / 30$ & 0 & 3 \\
$20 / 20$ & 0 & 4 \\
\hline
\end{tabular}

Table 3 Operative findings at presentation and subsequent surgeries on 29 patients with sutured ocular lacerations following the Beirut Blast

\begin{tabular}{ll}
\hline Intraoperative findings & \\
Expulsive choroidal hemorrhage & 8 \\
Retinal detachment & 6 \\
Traumatic or ruptured cataract & 9 \\
Eyelid laceration & 9 \\
Number of subsequent surgeries & \\
0 & 18 \\
1 & 11 \\
2 & 1 \\
3 & 3 \\
Subsequent surgery & \\
Pars plana vitrectomy & 7 \\
Evisceration & 2 \\
Intraocular lens implantation & \\
$\quad$ Primary & 6 \\
$\quad$ Secondary & 3 \\
Silicone oil removal & \\
Penetrating keratoplasty & 2 \\
Phacoemulsification & 3 \\
Lensectomy & 2 \\
\hline
\end{tabular}

$(p<0.001)$ (Table 4). ZOI inversely correlated with initial vision $(R=-0.40 ; p=0.02)$ and positively with final vision $(R=0.75 ; p<0.001)$. Visual gain correlated inversely with ZOI $(R=-0.63 ; p<0.001)$ and final vision $(R=-0.81$; $p<0.001)$. Final vision was significantly worse in zone 3 $(\log$ MAR $3.2 \pm 0.5)$ vs. zones 1 and $2(\log$ MAR $0.9 \pm 1.1)$ $(z$-score $=-4.2 ; p<0.001)$ injuries, as was the initial vision $(3.3 \pm 0.5$ vs. $2.7 \pm 0.8 ; z$-score $=-3.1 ; p=0.002)$. The eyes with retinal detachment had worse final vision than the eyes without retinal detachment $(2.5 \pm 0.9$ vs. $1.7 \pm 2.3$; $z$-score $=-1.1 ; p=0.3)$, but this was statistically not significant.

Ammonium nitrate (AN) is a detonable substance which has led to 16 major disasters from 1916 until the present day (Table 5). The combined total estimated weight of the exploding AN was 24,493 (mean 1750) tons. The number of deaths was 2443 (mean 152), the casualties 28,090 (mean 1873), and the ocular injuries 229 (mean 38, Table 5).

\section{Discussion}

The current 1-year postinjury report demonstrates the blinding sequelae of AN explosions (especially in the eyes with NLP or expulsive choroidal hemorrhage), and the recovery of vision in other patients (especially in the eyes with HM or better initial vision). The range of treatment included corneal transplant, intraocular lens implantation (primarily 
Table 4 Estimated probability of follow-up visual acuity category at 12-month (parentheses) vs. current findings in 29 patients with sutured ocular lacerations following the Beirut Blast (ZOI, zone of injury; $E C H$, expulsive choroidal hemorrhage)

\begin{tabular}{|c|c|c|c|c|c|c|c|c|}
\hline Raw score sum & OTS score & NLP & LP-HM & $1 / 200-19 / 200$ & $20 / 200-20 / 50$ & $\geq 20 / 40$ & zoi1,2,3 & $\mathrm{ECH}$ \\
\hline $0-44$ & 1 & $0(\mathbf{7 3} \%)$ & $0(\mathbf{1 7 \%})$ & $1(100 \%)(\mathbf{7 \%})$ & $0(\mathbf{2 \%})$ & $0(\mathbf{1 \%})$ & 1 zoi3 & 0 \\
\hline $45-65$ & 2 & $10(59 \%)(\mathbf{2 8 \%})$ & $2(17 \%)(\mathbf{2 6 \%})$ & $3(18 \%)(\mathbf{1 8 \%})$ & $0(\mathbf{1 3 \%})$ & $2(12 \%)(\mathbf{1 5 \%})$ & $\begin{array}{l}2 \text { zoi1 } \\
4 \text { zoi2 } \\
11 \text { zoi3 }\end{array}$ & 9 \\
\hline $66-80$ & 3 & $0(\mathbf{2 \%})$ & $1(7 \%)(\mathbf{1 1 \%})$ & $3(21 \%)(\mathbf{1 5 \%})$ & $4(29 \%)(\mathbf{2 8 \%})$ & $6(43 \%)(44 \%)$ & $\begin{array}{l}6 \text { zoi1 } \\
7 \text { zoi2 } \\
1 \text { zoi3 }\end{array}$ & 0 \\
\hline $81-91$ & 4 & $0(\mathbf{1 \%})$ & $0(\mathbf{2 \%})$ & $0(\mathbf{2 \%})$ & $0(21 \%)$ & $2(100 \%)(74 \%)$ & 2 zoi2 & 0 \\
\hline $92-100$ & 5 & $0(\mathbf{0 \%})$ & $0(1 \%)$ & $0(\mathbf{2 \%})$ & $0(\mathbf{5 \%})$ & $0(\mathbf{9 2} \%)$ & 0 & 0 \\
\hline Total & & 10 & 3 & 7 & 4 & 10 & $\begin{array}{l}8 \text { zoi1 } \\
13 \text { zoi2 } \\
13 \text { zoi3 }\end{array}$ & 9 \\
\hline
\end{tabular}

The values between brackets in bold rerpresent the estimated probability

or secondarily), and the full spectrum of vitreoretinal surgery. Most people's eyes were injured by glass shrapnel and debris. Two previous reports on the Beirut blast mentioned in great detail the large number of difficulties during the acute management of suturing the ocular wounds in a major general hospital (American University of Beirut; 6 cases)

Table 5 A historical record of ammonium nitrate explosions in chronological order (NA, not assessed)

\begin{tabular}{|c|c|c|c|c|c|c|}
\hline Year & City, country & $\begin{array}{l}\text { Estimated } \\
\text { weight in } \\
\text { tons }\end{array}$ & Fatalities & Wounded & Open eye & Remarks \\
\hline 2.4.1916 & Faversham, Kent, UK & 700 & 115 & 115 & NA & \\
\hline 21.9.1921 & $\begin{array}{l}\text { BASF Plant, Oppau, Ger- } \\
\text { many }\end{array}$ & 4500 & 561 & 1952 & $\begin{array}{l}\text { Several cases of ocular } \\
\text { injuries }\end{array}$ & $\begin{array}{l}7500 \text { homeless; } 1.7 \text { million } \\
\text { USD material damages }\end{array}$ \\
\hline 1.3.1924 & $\begin{array}{l}\text { Nixon Nitration Works, Edi- } \\
\text { son, New Jersey, USA }\end{array}$ & 3800 & 150 & 150 & NA & $\begin{array}{l}\text { Destruction of } 40 \text { buildings, } \\
\text { and the industrial town of } \\
\text { Nix demolition }\end{array}$ \\
\hline 29.4.1942 & $\begin{array}{l}\text { Factory in Tessenderlo, } \\
\text { Belgium }\end{array}$ & 150 & 189 & 900 & NA & \\
\hline 16.4.1947 & $\begin{array}{l}\text { Port of Texas City, Texas, } \\
\text { USA }\end{array}$ & 2300 & 581 & 3600 & 38 open eyes & $\begin{array}{l}100 \text { million USD material } \\
\text { damage }\end{array}$ \\
\hline 28.7.1947 & Ship in port Brest, France & 3300 & 29 & NA & NA & Port of Brest severely damaged \\
\hline 7.8.1959 & $\begin{array}{l}\text { Gerretsen Building Sup- } \\
\text { ply Company, Roseburg, } \\
\text { Oregon, USA }\end{array}$ & $4 \cdot 5$ & 14 & 25 & NA & \\
\hline 5.8 .1993 & Shenzhen, China & 91 & 15 & 141 & NA & \\
\hline 13.12.1994 & $\begin{array}{l}\text { Port Neal fertilizer plant, } \\
\text { Iowa, USA }\end{array}$ & 5700 & 4 & 18 & NA & Evacuation of 1700 residents \\
\hline 19.4.1995 & Oklahoma City, USA & 2.3 & 168 & 684 & 12 open eye & 652 million in material damage \\
\hline 21.9.2001 & AZF Toulouse, France & 400 & 31 & 2442 & 70 ocular injuries & $\begin{array}{l}\text { 30,000 damaged buildings; } 1.5 \\
\text { billion Euros in damage }\end{array}$ \\
\hline 22.4 .2004 & Ryongchŏn, North Korea & NA & 162 & 3000 & NA & 8000 homes destroyed \\
\hline 24.5.2004 & $\begin{array}{l}\text { Mihăilești, Buzău County, } \\
\text { Romania }\end{array}$ & 20 & 18 & 13 & NA & \\
\hline 17.4.2013 & $\begin{array}{l}\text { West Fertilizer Company } \\
\text { explosion, West, Texas, } \\
\text { USA }\end{array}$ & 30 & 15 & 252 & $31(12.3 \%)$ ocular injuries & \\
\hline 12.8 .2015 & Port of Tianjin, China & 800 & 173 & 798 & $18(2.3 \%)$ & \\
\hline 4.8.2020 & Port of Beirut, Lebanon & 2700 & 218 & 14,000 & $60(0.43 \%)$ & 300,000 homeless \\
\hline
\end{tabular}


[2] and the short-term results in EEI (31 cases) [3], while the current report details the 1 -year outcomes in 29 patients of the originally treated 42 patients with penetrating ocular injuries (among the 48 total cases of sutured lacerations as reported to the Lebanese Ophthalmic Society) [2].

A previous study showed that the most common surgeries performed following the Beirut blast were fractures, tendon repair, and suturing of ocular wounds (Table 3) [1]. This traumatic event with unique ophthalmological importance is reminiscent of the inordinate number of eye casualties following the 1917 Halifax Explosion [5]. When the 2 cargo ships Mont Blanc (loaded with munitions) and Imo collided and caught fire, residents rushed to their windows to watch the fire. As a result, 592 survivors sustained eye injuries caused by shards of shattered glass. Twelve ophthalmologists performed 249 enucleations ( 16 being bilateral) ending in 40 totally blind patients [5]. Although the total ocular surface $\left(17.6 \mathrm{~cm}^{2}\right)$ [14] constitutes only $0.1 \%$ of the total body surface $\left(18,000 \mathrm{~cm}^{2}\right.$ in men and 16,000 in women), the rate of reported ocular damage can be up to 50 times the body surface area [6]. Injuries caused by explosive materials are strongly associated with severe ocular morbidity and visual impairment $[4,7,10,15,16]$. In the Halifax disaster, 9000 people were injured, over 2000 died, 592 subjects had eye injuries, and 249 underwent nucleations (42.1\%). The general setup in 1917 included chloroform anesthesia and topical cocaine anesthesia, operating with the naked eye under the light of a bulb, use of commercially available silk sutures, and operating over a period of 4 days by a general eye ear nose throat practitioner. In the Beirut disaster a century later, 14,000 were injured, 219 died [1], 48 subjects underwent ocular surgery, and 4 received immediate enucleations $(8.3 \%)[2,3]$. The general setup included development of better instrumentation (operating microscope, vitrector, phacoemulsification, intraocular lens, intraocular magnet and forceps), smaller sutures with needles, use of viscoelastics, and prompt surgical management by vitreoretinal fellowship-trained ophthalmologists well trained in trauma management.

Most bodily injuries from AN involved the hand (Table 6) as many patients tried to protect their eyes with their hands. Hence, the ocular injuries would be expected to be much higher in the absence of the hand protection reflex. The exposure of the face in combat, and the vulnerability of the eye to even tiny flying particles explain the well-known susceptibility of the eyes to explosive injuries [6].

The OTS, which provides prognostic information after general ocular trauma, yields valuable prognostic information for AN-associated ocular injuries [17-20]. It appears that in explosive injuries, NLP initial vision and (intraoperative) expulsive choroidal hemorrhage are the most ominous prognostic variables. The effect of the development of retinal detachment did not appear to be significant on the final
Table 6 Admissions to the operating room (OR) within the first $52 \mathrm{~h}$ after Beirut Blast. There was a total of 534 total OR admissions out of 8643 emergency admissions in 42 medical centers [1]. The current table details the operations performed in 346 OR admissions in 13 major centers

\begin{tabular}{ll}
\hline Injury & $\begin{array}{l}\text { Operating room } \\
\text { admissions in 13 } \\
\text { centers }\end{array}$ \\
\hline Fractures & $127(36 \cdot 7 \%)$ \\
Hand & 22 \\
Arm & 36 \\
Face & 12 \\
Rest & 57 \\
Tendon repair & $68(19.7 \%)$ \\
$\quad$ Hand & 40 \\
Arm & 5 \\
$\quad$ Rest & 23 \\
Open eye & $50(14 \cdot 5 \%)$ \\
Craniotomy & $28(8 \cdot 1 \%)$ \\
Polytrauma & $26(7 \cdot 5 \%)$ \\
Major plastic surgery repair & $16(4 \cdot 6 \%)$ \\
Laparotomy & $6(1 \cdot 7 \%)$ \\
Thoracotomy & $4(1 \cdot 2 \%)$ \\
Foreign body removal (extremities 2, orbit 2) & $4(1 \cdot 2 \%)$ \\
Amputation (fingers 2, hand 1, foot 1) & $4(1 \cdot 2 \%)$ \\
Miscellaneous & $14(4.0 \%)$ \\
Total & $346(100 \%)$ \\
\hline
\end{tabular}

prognosis, although this may be due to its low incidence and to the concomitant complex ocular morbidities [18-21].

AN is highly explosive and can produce an overpressurization shock wave travelling to great distances, shattering glass in doors and windows. Footage of the blast consisted of several stages (Fig. 1) that starts with formation of a seminuclear orange mushroom-shaped cloud. The magnitude of the blast overpressure and the injuries are proportional to the amount of exploded AN and to the distance from the blast [1]. A second wave of injuries can occur due to the collapse of buildings or because of falling objects [22].

Besides terrorist attacks, most explosions are caused by fire during storage or transportation. Several actions are necessary to prevent such disasters [23]: (1) storage away from housing facilities, fuel tanks, or fireworks facilities; (2) adoption of strict storage-safety measures supervised periodically by local authorities; (3) UN surveillance of production and distribution of AN under the Terrorism Prevention Act.

Limitations of our study include its retrospective study design and the small number of patients. The latter is due the low percentage of patients returning for follow-up (13 out of 42 subjects were lost to followup) - partially explained by a large post-blast emigration wave. In addition, eye-injury patients with polytrauma 


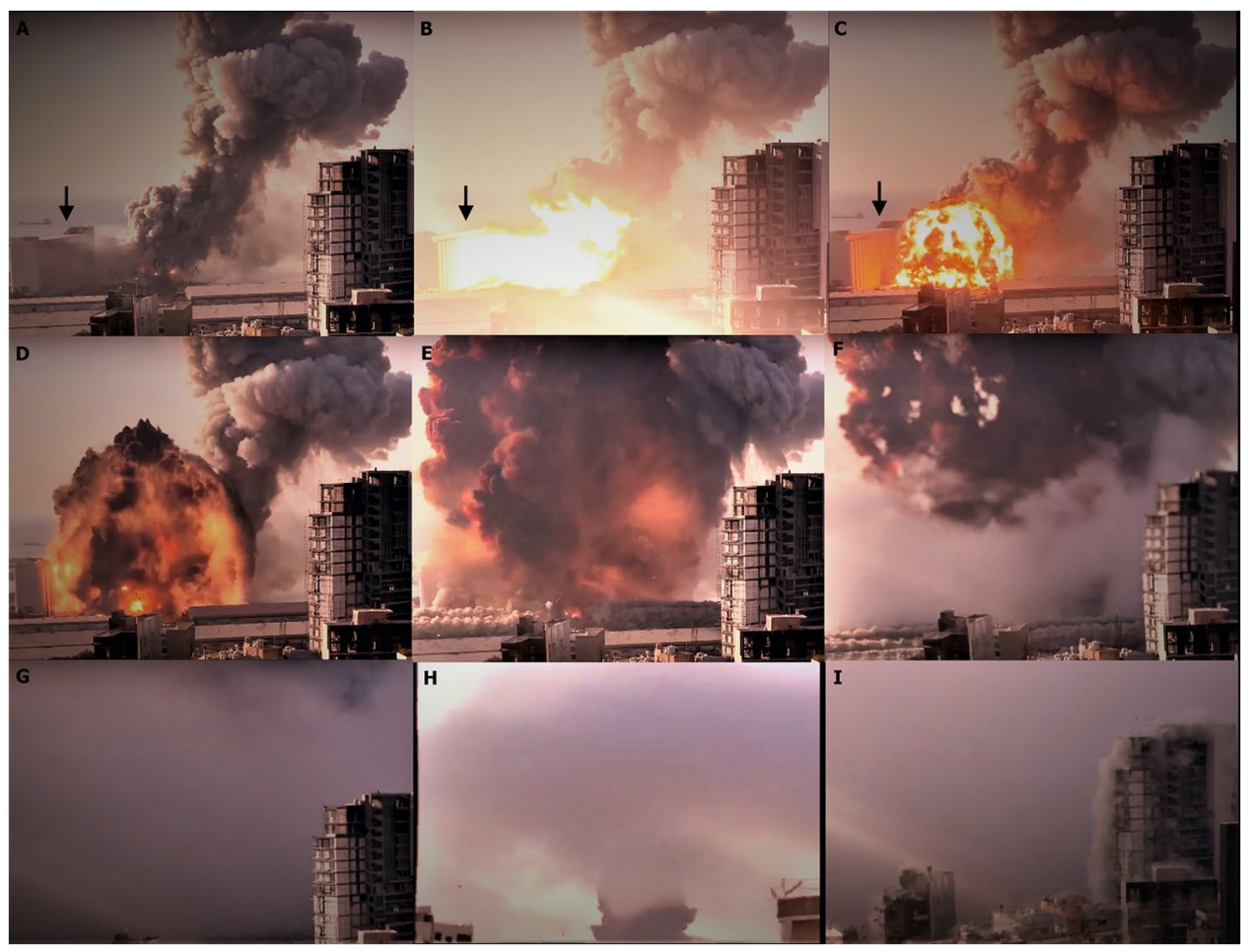

Fig. 1 Composite serial images of events at the Beirut Port at the time of the explosion (with written permission from the owner of the video footage by Nemeth Agoston on YouTube https://www.youtu be/rlvnsecLRmM). A A small explosion at a quayside building in the port of Beirut was followed by a fire from multiple firework explosions. B Several minutes later, a very big blast happened which also caused a huge shockwave. B Yellowish bright spark light; $\mathbf{C}$ then red smoke ball; D, E growing ball over microseconds; $\mathbf{F}, \mathbf{G}$ white cloud extend in all directions; $\mathbf{H}$ mushroom shape of the white cloud; I the blast shattering buildings. Half the explosive force radiated away almost harmlessly over the sea (west direction) and south wise the grain silo (arrow) dampened its effect tremendously leaving the northeastern part of the city to the full-blown effects. The red smoke visible before the shockwave is nitrogen dioxide, one of the chemicals produced when ammonium nitrate explodes. The white cloud during the main explosion is the shockwave making water in the air condense. Immediately behind the high-pressure shockwave, there is a sudden drop in pressure and temperature, leading to condensation of water in the air. The mushroom effect: the explosion produces a layer of hot gas that quickly rises. The air above blunts this hot gas as it tries to move upward, literally pushing it downward and forming the distinctive cap and life-threatening conditions were treated at a general hospital; only patients with isolated ocular injuries were admitted to the 2 major eye specialty hospitals. Orbital and adnexal injuries were not included and nonsurgical traumas (superficial corneal trauma, hyphema, etc.) were not ascertained in the current study.

In conclusion, we found that the OTS also provides reliable prognostic information on patients who sustained explosion (ammonium nitrate) injuries and who then undergo complex visual rehabilitation including pars plana vitrectomy for the surgical removal of intraocular foreign bodies, repair of retinal detachment, corneal transplant, and phacoemulsification or lensectomy with intraocular lens implantation. OTS may offer the possibility of approximation of the functional result in these patients before the surgery, and it is also helpful when triaging is necessary in cases of mass casualties. Expulsive choroidal hemorrhage and NLP vision remain very poor prognostic signs. Explosions of AN fertilizer in storage, transportation, or terrorism are preventable accidents and should be closely monitored by a UN special agency.

\section{Declarations}

Research involving human participants This retrospective chart review study involving human participants was in accordance with the ethical standards of the institutional and national research committee and with the 1964 Helsinki Declaration and its later amendments or comparable ethical standards. The Human Investigation Committee (IRB) of BESH and EEI hospitals approved this study.

Informed consent Informed consent was obtained from all individual participants included in the study.

Competing interests The authors declare no competing interests. 


\section{References}

1. Mansour HA, Bitar E, Fares Y et al (2021) The Beirut Port explosion: injury trends from a mass survey of emergency admissions. Lancet 398:21-22. https://doi.org/10.1016/S0140-6736(21) 01246-0

2. Kheir WJ, Awwad ST, Bou Ghannam A et al (2021) Ophthalmic injuries after the Port of Beirut blast-one of largest nonnuclear explosions in history. JAMA Ophthalmol 139:937-943. https:// doi.org/10.1001/jamaophthalmol.2021.2742

3. Sukkarieh G, Lahoud C, Ghorayeb R et al (2021) Characteristics of open eye injuries in the Beirut Port explosion. Injury 52:26012605. https://doi.org/10.1016/j.injury.2021.07.031

4. Wong TY, Seet MB, Ang C-L (1997) Eye injuries in twentieth century warfare: a historical perspective. Surv Ophthalmol 41:433-459. https://doi.org/10.1016/S0039-6257(97)00022-2

5. McAlister CN, Murray TJ, Lakosha $\mathrm{H}$ et al (2007) The Halifax disaster (1917): Eye injuries and their care. Br J Ophthalmol 91:832-835. https://doi.org/10.1136/bjo.2006.113878

6. Treister G (1969) Ocular casualties in the 6 Day War. Am J Ophthalmol 68:669-675. https://doi.org/10.1016/0002-9394(69) 91251-3

7. Mines M, Thach A, Mallonee S et al (2000) Ocular injuries sustained by survivors of the Oklahoma City bombing. Ophthalmology 107:837-843. https://doi.org/10.1016/s0161-6420(00) 00030-0

8. Jiang H, Xue C, Gao Y et al (2019) Analysis of ocular injury characteristics in survivors of the 8.12 Tianjin Port Explosion, China. J Ophthalmol 2019:1360805. https://doi.org/10.1155/2019/13608 05

9. Guo X-X, Li Z-J, Li H et al (2015) Organization and management of the treatment for the wounded in 8.12 Tinjin port explosion. China Chin J Traumatol 18:323-325. https://doi.org/10.1016/j. cjtee.2015.11.014

10. Gundogan FC, Akay F, Yolcu U et al (2016) Ocular blast injuries related to explosive military ammunition. J R Army Med Corps 162:39-43. https://doi.org/10.1136/jramc-2015-000408

11 Kuhn F, Morris R, Witherspoon CD et al (1996) A standardized classification of ocular trauma. Ophthalmology 103:240-243. https://doi.org/10.1016/s0161-6420(96)30710-0

12. Kuhn F, Maisiak R, Mann L et al (2002) The Ocular Trauma Score (OTS). Ophthalmol Clin North Am 15:163. https://doi.org/ 10.1016/s0896-1549(02)00007-x
13. Pittman W, Han Z, Harding B et al (2014) Lessons to be learned from an analysis of ammonium nitrate disasters in the last 100 years. J Hazard Mater 280:472-477. https://doi.org/10.1016/j. jhazmat.2014.08.037

14. Lim LS, Yang X, Gazzard G et al (2011) Variations in eye volume, surface area, and shape with refractive error in young children by magnetic resonance imaging analysis. Invest Ophthalmol Vis Sci 52:8878-8883. https://doi.org/10.1167/iovs.11-7269

15. Yonekawa Y, Hacker HD, Lehman RE et al (2014) Ocular blast injuries in mass-casualty incidents: the marathon bombing in Boston, Massachusetts, and the fertilizer plant explosion in West, Texas. Ophthalmology 121:1670-2166. https://doi.org/10.1016/j. ophtha.2014.04.004

16. Thach AB, Johnson AJ, Carroll RB et al (2008) Severe eye injuries in the war in Iraq, 2003-2005. Ophthalmology 115:377-382. https://doi.org/10.1016/j.ophtha.2007.04.032

17. Unal MH, Aydin A, Sonmez M et al (2008) Validation of the ocular trauma score for intraocular foreign bodies in deadly weaponrelated open-globe injuries. Ophthalmic Surg Lasers Imaging 39:121-124. https://doi.org/10.3928/15428877-20080301-15

18. Yaşa D, Erdem ZG, Demircan A et al (2018) Prognostic value of ocular trauma score for open globe injuries associated with metallic intraocular foreign bodies. BMC Ophthalmol 18:194. https:// doi.org/10.1186/s12886-018-0874-3

19. Ünver YB, Kapran Z, Acar N et al (2009) Ocular trauma score in open-globe injuries. J Trauma 66:1030-1032. https://doi.org/10. 1097/TA.0b013e3181883d83

20. Ahmadieh H, Soheilian M, Sajjadi H et al (1993) Vitrectomy in ocular trauma. Factors influencing final visual outcome. Retina 13:107-113. https://doi.org/10.1097/00006982-199313020-00003

21. Stryjewski TP, Andreoli CM, Eliott D (2014) Retinal detachment after open globe injury. Ophthalmology 121:327-333. https://doi. org/10.1016/j.ophtha.2013.06.045

22. Kurup SK, Que ET, Kauffmann Jokl DH (2002) The World Trade Center disaster: a brief on-site report from Ground Zero. Arch Ophthalmol 120:395-396

23. Babrauskas V (2016) Explosions of ammonium nitrate fertilizer in storage or transportation are preventable accidents. J Hazard Mater 304:134-149. https://doi.org/10.1016/j.jhazmat.2015.10. 040

Publisher's note Springer Nature remains neutral with regard to jurisdictional claims in published maps and institutional affiliations.

\section{Authors and Affiliations}

\section{Ahmad M. Mansour ${ }^{1}$ (D) - Daniel G. Cherfan ${ }^{2} \cdot$ Alex Jalkh $^{3} \cdot$ Ferenc Kuhn ${ }^{4,5,6}$}

1 Department of Ophthalmology, American University of Beirut, Beirut, Lebanon

2 Beirut Eye Specialty Hospital, University of Saint Joseph and Lebanese University, Beirut, Lebanon

3 Eye and Ear Hospital International, Faculty of Medicine, Holy Spirit University, Kaslik, Lebanon

4 Helen Keller Foundation for Research and Education, Birmingham, AL, USA
5 Department of Ophthalmology, University of Pécs Medical School, Pécs, Hungary

6 Department of Ophthalmology, Specialists of Alabama, University of Alabama, 2208 University Boulevard, Suite 101, Birmingham, AL 35233, USA 